\section{Screening for HCV}

We agree with Shah and colleagues ${ }^{1}$ that the growing burden of chronic hepatitis $\mathrm{C}$ virus (HCV) infection poses a substantial public health concern. Managing $\mathrm{HCV}$ is difficult, because HCV is clinically silent for the majority of those infected. If $\mathrm{HCV}$ is not recognized and patients are not treated, they may present with late-stage disease and potentially fatal complications. Universal screening and screening for HCV among high-risk groups in Canada are plausible strategies.

However, we need information on the potential effects on health, costs and cost-effectiveness of implementing either a universal or a selective screening program. A screening program will identify many people who require treatment, which will mean substantial costs to our health care system. Currently, cost is a salient issue because of the many new and expensive $\mathrm{HCV}$ treatment regimens in the drug pipeline. Although effective, these regimens are expensive (e.g., one approved drug costs about $\$ 45000$ for a 24-week course). Future drugs may be even more expensive ${ }^{2}$ and may cause adverse events.

We need to build a model that can project the health and economic effects of various HCV screening strategies conducted in different populations in Canada. Borrowing results from studies conducted in other countries may not reflect the situation (e.g., cost, patterns of care, disease epidemiology) in Canada.

Members of our group are collaborating with the Public Health Agency of Canada and the Canadian Agency for Drugs and Technologies in Health to perform economic evaluations on both screening as well as treatment for $\mathrm{HCV}$ in a Canadian setting. We hope that the results of our disease modelling will improve the scientific evidence around screening and drug treatment decisions.

\section{William W.L. Wong PhD, Murray} Krahn MD

Assistant professor (Wong); Director (Krahn), Toronto Health Economics and Technology Assessment (THETA) Collaborative, University of Toronto, Toronto, Ont.

\section{References}

1. Shah HA, Heathcote J, Feld JJ. A Canadian screening program for hepatitis $\mathrm{C}$ : Is now the time? CMAJ 2013;185:1325-8.

2. Common Drug Review Drug Database. Ottawa $(\mathrm{ON})$ : Canadian Agency for Drugs and Technologies in Health; 2012.

\section{CMAJ 2014. DOI:10.1503/cmaj.114-0016}

We applaud Shah and colleagues ${ }^{1}$ for raising the issue of establishing a Canadian screening program for hepatitis $\mathrm{C}$. We agree that hepatitis $C$ shows the hallmarks of an infectious disease suited to a screening program, ${ }^{2}$ but we are concerned that the extrapolation of American data into the Canadian context may hamper our ability to make a sound homegrown decision.

We do not think that Philadelphia clinic data from 2004-2005 or a 1999 national US survey provide valid evidence that " $[p]$ rimary care providers may be unaware of the risk factors for HCV infection" in Canada or that they "do not have time or knowledge to provide counselling." 1 Primary care involvement and expertise are appropriately central to screening programs in Canada, and we advocate for Canadian research on screening for hepatitis $\mathrm{C}$ in the context of primary care.

Cost-effectiveness estimates from the United States on screening those born between 1945 and 1965 are compelling but may not be relevant in Canada, given differences in access to health care services, and differences in the estimated hepatitis $\mathrm{C}$ prevalence in this birth cohort: $3.25 \%$ in the $\mathrm{US}^{3}$ and $1.2 \%$ in Canada. ${ }^{4}$

We suggest a systematic assessment of various screening strategies. Screening the 14 million people in this birth cohort, ${ }^{5}$ even once, would bear substantial opportunity costs. Targeted alternatives, such as screening on admission to correctional facilities, merit more consideration. There are 250000 admissions each year to correctional facilities in Canada; ${ }^{6}$ the hepatitis $\mathrm{C}$ prevalence in this setting is $18.7 \%$ overall and $61.3 \%$ among inmates who have injected drugs (about $30 \%$ of inmates). ${ }^{4} \mathrm{~A}$ targeted strategy in the correctional system could identify tens of thousands of people with hepatitis $\mathrm{C}$.
Fiona G. Kouyoumdjian MD MPH PhD, Aaron Orkin MD MSc MPH, Kathleen Dooling MD MPH, Michael Schwandt MD MPH

Postdoctoral fellow, Centre for Research on Inner City Health (Kouyoumdjian), St. Michael's Hospital; Dalla Lana School of Public Health (Orkin), University of Toronto, Toronto, Ont.; Peel Public Health (Dooling), Toronto, Ont.; Department of Community Health and Epidemiology (Schwandt), University of Saskatchewan, Saskatoon, Sask.

\section{References}

1. Shah HA, Heathcote J, Feld JJ. A Canadian screening program for hepatitis $\mathrm{C}$ : Is now the time? CMAJ 2013; 185:1325-8.

2. Wilson JMG, Jungner G. Principles and practice of screening for disease. Geneva: World Health Organization; 1968

3. Smith BD, Morgan RL, Beckett GA, et al. Hepatitis $C$ virus testing of persons born during 1945-1965: recommendations from the Centers for Disease Control and Prevention. Ann Intern Med 2012;157: 817-22.

4. Remis R. Modelling the incidence and prevalence of hepatitis $\mathrm{C}$ infection and its sequelae in Canada, 2007. Ottawa (ON): Public Health Agency of Canada; 2007.

5. Adult correctional statistics in Canada, 2010/2011 Ottawa (ON): Statistics Canada; 2012. Cat. no. 85-002-X.

6. Adult correctional services, admissions to provin cial, territorial and federal programs (Canada). Ottawa (ON): Statistics Canada; 2012; Available: www.statcan.gc.ca/tables-tableaux/sum-som/101/cst01 /legal30a-eng.htm (accessed 2013 Nov. 10).

CMAJ 2014. DOI:10.1503/cmaj.114-0017

\section{- Correction \\ The reverse is true}

An error appears in Figure 1 of the review article that appeared in the Apr. 2, 2013, issue of CMAJ. The figure indicates that during a spinal cord injury there is "decreased lactate and increased ATP [adenosine triphosphate]." This should read "increased lactate and decreased ATP." CMAJ apologizes for any confusion this error may have caused.

\section{Reference}

1. Wilson JR, Forgione N, Fehlings MG Emerging therapies for acute traumatic spinal cord injury. CMAJ 2013;185:485-92

CMAJ 2014. DOI:10.1503/cmaj.114-0021 